\title{
PENGARUH MICRO WAVE DIATHERMY DAN RHYTMICAL STABILISASI TERHADAP PERUBAHAN FUNGSIONAL SENDI LUTUT PENDERITA OSTEOARTRITIS DI BAGIAN FISIOTERAPI RMC MAKASSAR
}

\author{
Suriani, Suharto \\ Jurusan Fisioterapi Politeknik kesehatan Makassar
}

ABSTRAK

\begin{abstract}
Osteoarthritis is a chronic disease of cartilage, associated with secondary changes in cartilage, leading to joint inflammation and degeneration. Problems of pain and movement limitations can lead to decreased muscle strength as well as functional impairment in the knee joint, especially walking and up and down stairs. The purpose of this study was to determine whether there is an influence between MWD and Rhytmical Stabilization to functional changes in knee joints in osteoarthritis patients in physiotherapy RMC Makassar. This research is a pre experimental study with pretest-post test design one group design. Research subjects as many as 10 people who have knee osteoarthritis who went to the physiotherapy of Ratulangi Medical Center Makassar. Sampling by accidental sampling during the study was conducted. The results showed a significant difference before - after administration of MWD and Rhitmical stabilization to functional ability of patient walking knee osteoarthritis with average difference of $2.00 \mathrm{~cm} \pm 0,00$ with Wilcoxon Signed Ranks Test test $p=0,002$ and for functional capability up and down ladder obtained by difference of mean equal to $1,10 \pm 0.316$ with $p=$ 0.002 . The conclusion of this study is the increase in walking ability and up and down stairs of patients with knee osteoarthritis after given MWD and Rhitmical stabilization.
\end{abstract}

Keywords: Micro Wave Diathermy, Rhytmical Stabilization, Functional, OA knee

\section{Latar Belakang Masalah}

Osteoarthritis (OA) merupakan bentuk arthritis yang paling sering dijumpai dengan kerusakan pada cartilago sendi. Diantara lebih dari 100 jenis penyakit sendi yang dikenal maka osteoarthritis merupakan kelainan sendi yang paling sering ditemukan. Insiden OA di RS. Cipto Mangunkusumo pada tahun 1990 menunjukkan bahwa pada usia $<20$ tahun hanya sekitar 20\% penderita OA dan meningkat menjadi > $80 \%$ pada usia diatas 55 tahun (Harry Isbagio, 1995).

Di Inggris dan Wales, sekitar 1,3 sampai 1,75 juta orang mengalami osteoartritis, 500.000 di antaranya menderita osteoartritis lutut parah. Osteoartritis menyebabkan disabilitas nomor dua setelah penyakit kardiovaskular (Haq dkk, 2003: 377). Penelitian epidemiologi di Bandung dan Jawa Tengah terhadap 4693 responden menunjukkan bahwa ditemukan arthritis rematoid sekitar 0,3\%, arthritis gout sekitar $1,7 \%$ pada pria, osteoarthritis knee joint ditemukan sekitar $14 \%$, osteoarthritis lumbal dan cervical sekitar $5 \%$ dan $4 \%$, sedangkan fibrositis bahu sekitar $13,9 \%$ pada pria dan $14,9 \%$ pada wanita serta epicondylitis sekitar $5 \%$ pada pria dan $6,1 \%$ pada wanita (Harry Isbagio, 1995). Berdasarkan penelitian di Malang tahun 1994 dijumpai penderita osteoarthritis knee joint sekitar $10 \%$ daerah perkotaan dan $13,5 \%$ daerah pedesaan, sedangkan di Bandung tahun 1992 dijumpai penderita osteoarthritis knee joint sekitar 18\% daerah perkotaan dan 5,4\% daerah pedesaan (Yoga I Kasjmir, 2009).

Osteoarthritis sendi lutut menyerang pada usia antara 45-64 tahun yang mencapai $30 \%$ dan persentasinya mengalami peningkatan pada usia di atas 65 tahun yakni 63 $85 \%$. Osteoarthritis bukan merupakan ancaman hidup tapi dapat menurunkan kualitas hidup seseorang akibat nyeri yang diderita serta gangguan gerak sendi yang dialami (Chriss Sorrell, 2005). Sendi lutut merupakan sendi yang paling besar menerima beban saat berdiri, berjalan dan berlari. Secara topografi, sendi lutut terletak antara hip joint dan ankle jointsehingga menerima beban yang besar dari atas dan beban gaya gravitasi dari bawah. Sedangkan secara fungsional, Sendi lutut sangat penting dalam berbagai aktivitas fungsional seperti berjalan, berlari, menendang dan jongkok-berdiri.

Osteoarthritis lebih banyak menyerang pada wanita daripada lakilaki dengan rasio $2: 1$, dan terutama lebih banyak pada wanita diatas usia 50 tahun tetapi tidak ada fakta yang menunjukkan hubungan dengan menopause. Osteoarthritis juga lebih banyak menyerang pada beberapa kelompok suku bangsa sebagai contoh, 
osteoarthritis lebih banyak menyerang pada orang-orang kulit hitam daripada orang-orang kulit putih (Kay J. Brimeyer, 2005). Hasil observasi di bagian fisioterapi RMC Makassar bulan Januari s/d Maret 2015 didapatkan 12 orang penderita OA sendi lutut yang berobat ke Fisioterapi.

Kasus osteoarthritis sendi lutut menimbulkan problem utama yaitu nyeri dan keterbatasan gerak. Nyeri pada kondisi ini dapat diperburuk setelah melakukan aktivitas dan kekakuan dapat diperburuk setelah duduk dalam waktu yang lama terutama duduk bersila atau duduk melantai. Problem nyeri dan keterbatasan gerak dapat menyebabkan penurunan kekuatan otot serta gangguan fungsional padas sendi lutut terutama aktivitas berjalan dan naik turun tangga yang akhirnya dapat menurunkan produktivitas seseorang dalam pekerjaannya.

Untuk menyelesaikan problem yang dihadapi pasien OA sendi lutut fisioterapi dapat memberikan penanganan berupa Micro Wave Diathermy (MWD) dan Rhythmical Stabilisasi sehingga dapat memulihkan gerak dan fungsi sendinya karena MWD dan Rhytmical Stabilisasi dapat menurunkan nyeri dan peningkatan stabilitas sendi lutut.

\section{Tujuan Penelitian}

1. Tujuan Umum

Untuk mengetahui pengaruh MWD dan Rhytmical Stabilisasi terhadap perubahan fungsional sendi lutut pada pasien OA di bagian fisioterapi RMC Makassar.

2. Tujuan Khusus

a. Mengetahui kemampuan fungsional berjalan dan naik turun tangga penderita osteoarthritis sendi lutut sebelum diberikan MWD dan Rhytimcal stabilisasi

b. Mengetahui kemampuan fungsional berjalan dan naik turun tangga penderita osteoarthritis sendi lutut setelah diberikan MWD dan Rhytimcal stabilisasi

c. Mengetahui pengaruh MWD dan Rhytmical stabilisasi terhadap perbaikan fungsional berjalan dan naik turun tangga penderita osteoarthritis sendi lutut

\section{Metode Penelitian Jenis Penelitian}

Jenis penelitian yang di gunakan dalam penelitian ini adalah pra experiment dengan menggunakan desain penelitian pretest - posttest one group design.

\section{Tempat dan waktu penelitian}

Penelitian dilaksanakan di bagian Fisioterapi RMC Makassar mulai Maret s/d Mei 2015.

\section{Populasi dan Sampel}

\section{Populasi penelitian}

Populasi penelitian adalah semua penderita osteoarthritis sendi lutut yang berobat di bagian Fisioterapi RMC Makassar

\section{Sampel penelitian}

Sampel penelitian adalah semua penderita osteoarthritis sendi lutut yang memenuhi kriteria sebanyak 10 orang.

\section{Teknik Pengambilan Sampel}

Pengambilan sampel di lakukan dengan teknik accidetntal sampling dan memenuhi kriteria yang ditetapkan oleh peneliti, yaitu : (1) penderita osteoarthritis sendi lutut berdasarkan hasil assessment fisioterapi dan pemeriksaan radiologi dan (2) bersedia ikut dalam penelitian ini.

\section{Teknik Pengumpulan Data}

Dilakukan dengan cara mencatat identitas penderita dan melakukan pemeriksaan fisioterapi dan melihat hasil pemeriksaan X-ray dilanjutkan dengan mengukur fungsional sendi lutut pada setiap sampel untuk mendapatkan data pre test dan post tes. Adapun alat ukur yang digunakan adalah mengukur kemampuan berjalan dan naik turun tangga.

\section{Analisa dan pengolahan data}

Teknik pengolahan dan analisa data menggunakan bantuan program SPSS (Statistical Product For Service 
Solution) dengan Wilcoxon sign rank test.

\section{HASIL PENELITIAN}

\section{Karakteristik Responden}

Penelitian ini dilaksanakan di Klinik Fisioterapi Ratulangi Medical Centre Makassar (RMC) dengan populasi penelitian semua penderita osteoarthritis lutut yang berkunjung di bagian fisioterapi RMC Makassar dari bulan Maret sampai dengan Mei 2015. Karakteristik subjek penelitian dapat dilihat berdasarkan usia dan jenis kelamin pada tabel 1 dibawah ini.

Tabel. 1

Distribusi Responden berdasarkan Usia dan Jenis Kelamin

\begin{tabular}{|l|c|c|}
\hline \multicolumn{1}{|c|}{$\begin{array}{c}\text { Karakteristik } \\
\text { Responden }\end{array}$} & $\mathrm{n}$ & $\%$ \\
\cline { 2 - 3 } & & \\
\hline Kelompok usia : & 2 & 20 \\
$<60$ tahun & 8 & 80 \\
\hline 60 tahun & & 60 \\
\hline $\begin{array}{l}\text { Jenis kelamin : } \\
\text { Laki-laki } \\
\text { Perempuan }\end{array}$ & 6 & 40 \\
\hline Jumlah & 4 & 100 \\
\hline
\end{tabular}

Tabel diatas menunjukkan distribusi responden berdasarkan kelompok usia dan jenis kelamin kelompok perlakuan. Pada kelompok perlakuan menunjukkan bahwa lebih banyak responden yang berusia $\geq 60$ tahun yaitu 8 orang $(80 \%)$ dari pada responden yang berusia $<60$ tahun yaitu $20 \%$ dan lebih banyak responden laki-laki yaitu 6 orang $(60 \%)$ dari pada perempuan.

2. Analisis kemampuan fungsional berjalan sebelum dan sesudah

\section{pemberian MWD dan Rhytmical stabilisasi}

Pengukuran kemampuan fungsional berjalan pada subjek penelitian yang mengalami osteoarthtritis di lakukan dua kali yaitu sebelum diberikan MWD dan Rhytmical stabilisasi. Setelah perlakuan diberikan sebanyak 6 kali kepada setiap subjek penelitian, maka segera dilakukan pengukuran kemampuan fungsional berjalannya. Untuk lebih jelasnya dapat dilihat pada tabel 2 di bawah.

Tabel 2

Distribusi kemampuan fungsional berjalan Pre test dan Post test pada kelompok perlakuan

\begin{tabular}{|lccc|}
\hline Kondisi & Nilai Rerata & Standar Deviasi & $\mathrm{n}$ \\
\hline Perlakuan & & & \\
Pre test & 5.00 & 1.054 & 10 \\
Post test & 7.00 & 1.054 & \\
Selisih & 2.00 & 0.000 & \\
\hline
\end{tabular}

Tabel diatas menunjukkan nilai rerata dan standar deviasi pada kelompok perlakuan diperoleh nilai rerata pre test sebesar $5,00 \pm 1,054$ dan nilai rerata post test sebesar $7,00 \pm 1,054$ dengan nilai rerata selisih sebesar $2.00 \pm 0,000 \mathrm{Hal}$ ini menunjukkan adanya perubahan atau penurunan nyeri setelah diberikan $M W D$ dan Rhytmical stablisasi. 
3. Analisis kemampuan fungsional naik turun tangga sebelum dan sesudah pemberian MWD dan Rhytmical stabilisasi

Pengukuran kemampuan fungsional naik turun tangga sama dengan pengukuran kemampuan berjalan. Setelah diberikan perlakuan sebanyak 6 kali kepada setiap subjek penelitian, maka segera dilakukan pengukuran kemampuan fungsional naik turun tangga. Untuk lebih jelasnya dapat dilihat pada tabel 3 di bawah.

Tabel. 3

Distribusi nilai fungsional naik turun tangga Pre test dan Post test pada Kelompok Perlakuan

\begin{tabular}{|lccc|}
\hline Kondisi & Nilai Rerata & Standar Deviasi & $\mathrm{n}$ \\
\hline Perlakuan & & & \\
Pre test & 2,50 & 0,527 & 10 \\
Post test & 3,60 & 0,516 & \\
Selisih & 1,10 & 0,316 & \\
\hline
\end{tabular}

Tabel diatas menunjukkan nilai rerata dan standar deviasi pada kelompok perlakuan diperoleh nilai rerata pre test sebesar 2,50 $\pm 0,527$ dan nilai rerata post test sebesar $3,60 \pm 0,516$ dengan selisih nilai rerata sebesar $1,10 \pm 0,316$. $\mathrm{Hal}$ ini menunjukkan adanya perubahan atau peningkatan fungsional berjalan setelah diberikan MWD dan Rhytmical stabilisasi.

Pada uji statistik juga diperoleh perubahan nilai kemampuan fungsional berjalan dan naik turun tangga sebelum dan sesudah pemberian MWD dan Rhytmical stabilisasi secara signifikan dengan nilai $p=0,002$. Hal ini menunjukkan bahwa pemberian $M W D$ dan Rhytmical stabilisasi dapat menghasilkan pengaruh yang bermakna terhadap peningkatan fungsional berjalan dan naik turun tanggapenderita osteoarthritis sendi lutut.

\section{PEMBAHASAN}

\section{Karakteristik Responden}

Pada penelitian ini jumlah responden sebanyak 10 orang dan lebih banyak responden yang berusia $\geq 60$ tahun yaitu $80 \%$ dan lebih banyak responden laki-laki yaitu $60 \%$. Penderita osteoarthritis sendi lutut umumnya mengenai usia 60 tahun ke atas, karena usia merupakan faktor utama yang bertanggung jawab terhadap perkembangan osteoarthritis sendi lutut. Seseorang yang terkena osteoarthritis makin bertambah seiring dengan bertambahnya usia dan biasanya terjadi pada orang yang berusia 45 tahun ke atas, lakilaki di bawah umur 55 tahun lebih sering menderita penyakit ini dibanding perempuan pada usia yang sama.

Proses penuaan diperkirakan menjadi penyebab kelemahan di sekitar sendi, berkurangnya propriosepsi sendi, kalsifikasi kartilago, dan berkurangnya fungsi kondrosit. Prevalensi osteoartritis meningkat sesudah umur 40 tahun pada wanita dan 50 tahun pada pria. Osteoartritis dialami sekitar $50 \%$ orang berusia 65 tahun ke atas dan prevalensinya meningkat menjadi 85 $\%$ pada kelompok usia 75 tahun ke atas. (Haq dkk, 2003). Laki-laki usia 50 tahun ke bawah mempunyai prevalensi dan insidensi lebih tinggi daripada wanita. Namun demikian, pada usia lebih dari 50 tahun, wanita mempunyai prevalensi dan insidensi lebih banyak daripada laki-laki. Turunnya kadar estrogen saat menopause mungkin menjadi pemicu munculnya osteoartritis. Osteoartritis tangan dan lumt lebih sering pada wanita, sedangkan osteoartritis panggul lebih tinggi pada pria (Haq dkk, 2003) 
2. Kemampuan fungsional berjalan dan naik turun tangga sebelum dan sesudah pemberian MWD dan Rhytmical stabilisasi

Hasil penelitian menunjukkan bahwa pemberian MWD dan Rhytmical stabilisasi dapat meningkatkan kemampuan fungsional berjalan dan naik turun tangga secara bermakna pada penderita osteoarthritis sendi lutut. MWD menghasilkan efek thermal dengan daya penetrasi yang dalam dapat meningkatkan elastisitas pada otot dan jaringan ikat, disamping itu dapat menurunkan spasme otot melalui efek sedatif pada ujung-ujung saraf sensorik dan peningkatan metabolisme jaringan (William $\mathrm{E}$. Prentice, 2003 dan Dwidayani A,2008). Efek terapeutik yang dihasilkan oleh MWD tersebut memudahkan intervensi Rhytmical stabilisasi terhadap peningkatan fungsional berjalan dan naik turun tangga.

Penelitian ini sejalan dengan penelitian Dixon J. et al, (2002) yang berjudul "Quadriceps and hamstring force development in patients with osteoarthritis of the knee "yang dimuat dalam abstracts $14^{\text {th }}$ International WCPT Conggress 2003 di Australia mendapatkan hasil peningkatan yang bermakna terhadap pengurangan nyeri, kualitas hidup dan fungsional berjalan pada pasien dengan OA lutut. Dengan latihan penguatan otot quadriceps akan memperbaiki stabilitas sendi lutut, mengurangi nyeri, memperlancar sirkulasi darah sekitar persendian dan nutrisi tulang rawan dan memberbaiki kekuatan dan fungsi jaringan sekitar sendi seperti capsul sendi, ligamen, tendon yang sering rusak akibat adanya Osteoarthrosis (The University Of Melbourne, 2007).

Pemberian Latihan Stabilisasi sendi lutut lebih mengarahkan pada stabilitas sendi secara aktif. Stabilitas aktif sendi dihasilkan oleh otot quadriceps dan hamstring sehingga latihan ini sebenarnya diarahkan pada penguatan otot quadriceps dan hamstring. Latihan stabilisasi dengan teknik rhytmical stabilisasi dan dynamik stabilisasi dapat menghasilkan kontraksi yang multiple dari otot antagonis-agonis. Teknik rhytmical stabilisasi, otot stabilisator sendi lutut difasilitasi untuk kontraksi maksimal pada titik lingkup gerak sendi yang paling kuat. Sedangkan teknik Dynamik Stabilisasi, diaplikasikan latihan-latihan yang menumpuh berat badan dengan penekanan pada sendi yang terganggu. Dengan latihan ini diharapkan terjadi peningkatan kekuatan otot yang mempertahankan stabilitas sendi lutut

Penelitian lain oleh DiNubile (1997) menyatakan bahwa Latihan peregangan dan latihan aktif dapat meningkatkan range of motion (ROM) serta memperbaiki dan mempertahankan mobilitas sendi pasien osteoarthritis sendi lutut. Aktivitas fungsional yang melibatkan sendi sangat membutuhkan kekuatan otot quadriceps dan hamstring sebagai penggerak utama dan stabilitas utama pada sendi lutut. Pemberian latihan stabilisasi dengan tahanan isometrik secara open kinematik dan closed kinematik dapat merangsang kekuatan otot quadriceps dan hamstring sehingga terjadi peningkatan kekuatan otot tersebut secara progresif. Peningkatan kekuatan otot akan menunjang kemampuan sendi didalam melakukan aktivitas fungsional sehingga dapat terjadi peningkatan kemampuan berjalan dan naik turun tangga pada penderita.

\section{Kesimpulan}

Pemberian MWD dan Rhytmical stabilisasi dapat meningkatkan kemampuan fungsional berjalan dan naik turun tangga penderita OA knee secara signifikan sehingga berguna untuk perbaikan aktivitas sehari-hari penderita.

\section{Ucapan terima kasih}

Terima kasih kami sampaikan kepada direktur Politeknik Kesehatan Kemenkes Makassar yang telah memberikan kesempatan untuk melaksanakan penelitian, terima kasih 
kami sampaikan juga kepada Ketua Jurusan Fisioterapi Politeknik Kesehatan Makassar yang memberikan izin untuk melaksanakan penelitian ini dan kepada teman-teman serta subjek penelitian yang ikut dalam penelitian ini.

\section{DAFTAR PUSTAKA}

American geritrics society. 2001. "Exercise Prescription for Older Adults with Osteoarthritis Pain: Consensus Practice Recommendation

Ann Thomson et.al, 1991. Tidy's Physiotherapy, Twelth Edition, Butterworth Heinemann, Oxford.

Carolyn Kisner, Lynn Allen Colby, 2007. Therapeutic Exercise Foundations And Techniques, Fifth Edition, F.A. Davis Company, Philadelphia.

Chriss Sorrell, 2005. Osteoarthritis Of The http://www.arc.org.uk/arthinfo, akses tanggal 21 Juni 2015.

Darlene Hertling, Randolph M. Kessler, 2006. Management of Common Musculoskeletal Disorders, Fourth Edition, Lippincott Williams \& Wilkins, Philadelphia.

DiNubile, N.A. 1997. "Osteoarthritis: How to Make Exercise Part of Your Treatment Plan." The Physician sportmedicine, vol.25, no.7: 1-10.

Dwidayani A,2008, Perbedaan pengaruh Intervensi MWD dan Isometrik Quadriceps dengan TENS dan Isometrik Quadriceps terhadap penurunan rasa nyeri (tidak di publikasikan).

DY Wen, 2009. Osteoarthritis Of The Knee,

http://www.aafp.org/afp/20000801 /565.html, akses tanggal 21 Juni 2015.
Haq, I., Murphy, E. , \& Dacre, J. (2003). "Osteoarthritis." Postgrad Med J; 9:377-83.

Harry Isbagio, 1995. Masalah Nyeri Kejang Otot Pada Penderita Penyakit Reumatik, Cermin Dunia Kedokteran,

http://www.kalbe.co.id/files/cdk/ osteoarthritis.pdf, akses tanggal 20 Juni 2015.

Karen Atkinson et al, 2000. Phyisotherapy in Orthopaedics A Problem-Solving Approach, Churchill Livingstone, Edinburgh.

Kay J. Brimeyer, 2005. Arthritis of The Knee Joint, http://www.hipsandknees.com knee/kneearthritismeds.htm, akses tanggal 19 Juni 2015.

Kevin E. Wilk et al, 1994. The Relationship Between Subjective KneeScores, Isokinetic Testing, and Functional Testing in the ACLreconstructed knee, Journal of Orthopaedic \& Sports Physical Therapy.

Soekidjo Notoatmodjo, 2002. Metode Penelitian Kesehatan, Rineka Cipta, Jakarta.

Sugiyono, 2007. Statistika Untuk Penelitian, CV. Alfabeta, Bandung.

William C. Shiel Jr, 2005. Osteoarthritis (Degenerative Arthritis), http://www.arthritis.org, akses tanggal 20 Juni 2015.

William E. Prentice, 2003.Therapeutic Modalaties For Sport Medicine and Athletic Training, Fifth Edition, Mc Graw Hill, New York.

Yoga I Kasjmir, 2009. Penatalaksanaan Osteoarthritis, http://www.irwanashari. com/ 2009/03/penatalaksanaanosteoartritis.html, akses tanggal 19 Juni 2015. 